\title{
Study the Effect of Imposing Surfactants toward the Evaporation of Low Molecular Weight Alcohol
}

\author{
Mohammad Hafiz Hamzah, Sharifuddin Mohd Zain, Rashid Atta Khan, Khalisanni Khalid
}

\begin{abstract}
In this paper, Reversed-Flow Gas Chromatography (RF-GC) is utilized to investigate the evaporation of low molecular weight alcohol. Evaporation rates as well as the diffusion rates of methanol are determined with a surfactant monolayer on the surface of the liquid; while nitrogen acts as carrier gas, at $313 \mathrm{~K}$. The precision $(>99.9 \%)$ and accuracy of this investigation demonstrates the potential of current methodologies for environmental impact studies; this is further verified when the results are compared with the available literature. The varying evaporation rates of methanol in the presence of varying amounts of Triton X-100 reflects that application of surfactants do damper the evaporation rates of liquid pollutants; without interference with the former's diffusion coefficients. High amounts of Triton X-100 are required for retardation of evaporation rates, suggesting the formation of a densely packed surface monolayer or the formation of an insoluble monolayer.
\end{abstract}

Index Terms-Evaporation, diffusion coefficients, rate coefficients, surfactants.

\section{INTRODUCTION}

The ecological fate and evaporation of pollutant liquids are co-related to each other, especially when the compounds are introduced into both freshwater and marine environments through industrial effluents, or introduced directly into the air from industrial unit process units such as bioreactors and cooling towers [1]. The process is highly dependent on the concentration of the pollutant liquid, it will travel according to the concentration gradient, i.e. from high concentration to low concentration of the respective liquid. There are barriers that contribute to the evaporation rate [3] which includes the "stagnant" gaseous and liquid layer close to the surface, across which the vapor must diffuse. One area of application is industrial accidents, for example such as when the MV Bunga Alpinia 3 exploded while being loaded with methanol on 26 July 2012 at the PETRONAS jetty in Labuan [2]. As a result, methanol - one of the liquids under study, spilled into the sea near Labuan. The Reversed-Flow Gas Chromatography (RF-GC) method can be used as an indicator to 'measure' the evaporation rates of liquid

Manuscript received March 24, 2013; revised May 2, 2013. This work was supported in part by the University of Malaya under Grant RG045/09SUS.

M. H. Hamzah, S. M. Zain, and R. A. Khan are with the Chemistry Department University of Malaya, K.L., Malaysia (e-mail: enal_fifi@yahoo.com; smzain@um.edu.my;dr_rashid@um.edu.my).

$\bar{K} . i$ Khalid was with Chemistry Department University of Malaya, K.L., Malaysia. He is now with Food and Agricultural Analysis Laboratory Program, Technical Service Centre, Malaysian Agricultural Research and Development Institute (MARDI), 43400 Serdang, Selangor, Malaysia. (e-mail: typhloids@hotmail.com). pollutants and can quickly guide actions to be taken by the respective authorities, such as applying a suitable surfactant to curb the methanol from being evaporated into the air - this effort will help prevent the people nearby from inhaling the hazardous vapors of methanol. This may be possible if the application of surfactant on the liquid pollutant results a drastic retardation of the evaporation rate, mainly because of the presence of adsorbed monolayers [3]. Because RF-GC sampling is fast and accurate, it is a reliable method to investigate how much liquid pollutant has been evaporated into the air. Besides that, the methodologies can also embrace the area of food chemistry, chemical kinetics, catalyst and catalysis [4]. Surfactants which form monolayers at the air-liquid interface have been found to cause a significant reduction in the evaporation rate of water. Long chain alcohols decrease the evaporation rate of the water on an actual lake by a factor of $46-50 \%$ [16-22]. This paper demonstrates the utilization of RF-GC in the study of evaporation of a low molecular alcohol weight (methanol), with various amounts of the nonionic surfactant Triton $\mathrm{X}-100$.

\section{Methodology}

\section{A. Preparation of the TritonX-100-methanol solution}

The Gibbs adsorption equation (solutions of nonionic surfactants) as stated below [5]

$$
\Gamma_{1}=-\frac{1}{2.303 R T}\left(\frac{\partial \gamma}{\partial \log C}\right)
$$

is used to prepare the various Triton $\mathrm{X}-100$ - methanol solutions in order to determine the amount of Triton X-100 per unit area.

- $\quad \gamma$ is the surface tension in N.m ${ }^{-1}$ initially and then converted to J.m $\mathrm{m}^{-2}$.

- $C_{1}$ is the molar concentration of the surfactant at the experimental absolute temperature $T=298.15 \mathrm{~K}$

- $R=8.314 \mathrm{~J} \cdot \mathrm{mol}^{-1} \cdot \mathrm{K}^{-1}$ is the ideal gas constant

- $\Gamma_{1}$ is the surface excess constant of the surfactant in $\mathrm{mol} \cdot \mathrm{m}^{-2}$.

The surface tension, $\gamma$ is plotted against the $\log$ of the concentration, $C_{1}$ to determine the surface area per molecule, $\alpha_{1}^{s}$ as shown in Fig. 1 


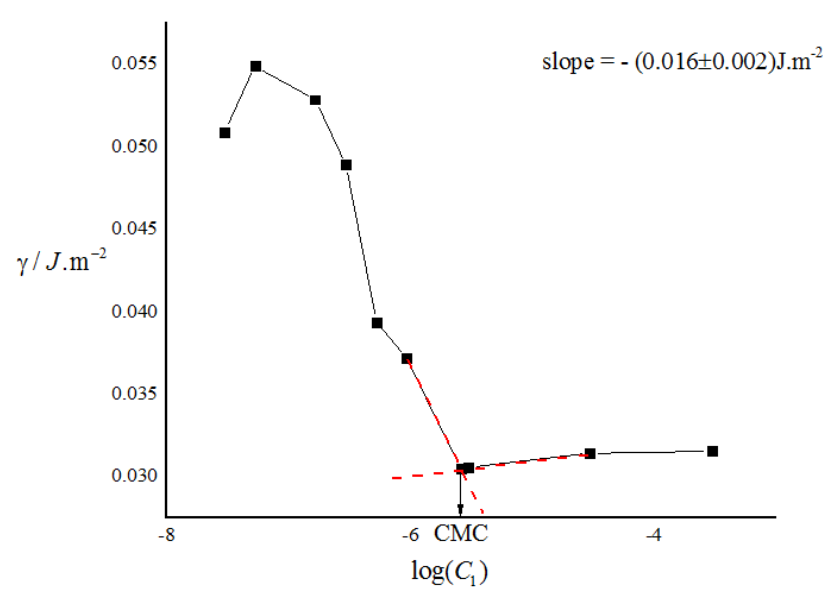

Fig. 1. Plot of the surface tension $\left(\gamma / \mathrm{J} \cdot \mathrm{m}^{-2}\right)$ against the $\log$ of $C_{1}$, where $C_{1}$ is the bulk phase concentration of the various aqueous solutions of Triton X-100 surfactant, at $298.15 \mathrm{~K}$.

** $\mathrm{CMC}=$ Critical micelle concentration Surface tension measurements were performed by using a Kruss Tensiometer K100.

The surface excess concentration of Triton X-100 was calculated: $\Gamma_{1}=(2.78 \pm 0.04) 10^{-6} \mathrm{~mol} . \mathrm{m}^{-2}$ by using the slope of Fig. 1. From the value $\Gamma_{1}$ obtained, a specific surface area per molecule at the interface was calculated as follows [6]:

$$
\alpha_{1}^{s}=\frac{10^{20}}{N_{A} \Gamma_{1}}
$$

where $N_{A}$ is Avogadro's number and $\Gamma_{1}$ is in mol.m ${ }^{-2}$. The value of $\alpha_{1}^{s}$ was found as $(5.975 \pm 0.080) .10^{-9} \mathrm{~m}^{2}$.The values of $\Gamma_{1}$ and $\alpha_{1}^{s}$ were found with the same magnitude of the similar homologous head group of nonionic surfactants given on the page 78 of Ref 5. The $\mathrm{CMC}^{* *}$ for the aqueous solutions of Triton X-100 was found to be $C_{1}=2.57 .10^{-4} \mathrm{M}$ or $0.0002 \%$ vol. The theoretical coverage of the Triton X-100 monolayer, ranging from 1 to 4 monolayers was determined [3], since the surface area of the bottle containing the evaporating liquid under study, $\mathrm{a}_{\mathrm{L}}$ as well as the specific surface area per molecule at the interface, $\alpha_{1}^{s}$ were known.

\section{B. Materials}

The solutes used as evaporating liquids (stationary phase) were Merck "SupraSolv" (methanol) and TritonX-100 (iso-Octylphenoxypolyethoxyethanol, $d=1.06 \mathrm{~g} . \mathrm{ml}^{-1}$ and $M$ $\left.=646.37 \mathrm{~g} \cdot \mathrm{mol}^{-1}\right)$. Purified nitrogen (99.9\% purity) supplied by Malaysian Oxygen Berhad (MOX) was used as the carrier gas (mobile phase). Hydrogen and compressed air used to fuel the FID were supplied by MOX as well.

\section{Techniques}

The apparatus used and the experimental procedure followed have been described elsewhere [8],[9]. A conventional gas chromatograph (Shimadzu, Series GC-14B) with a flame ionization detector (FID) and Shimadzu Solution as the software program was used for this experiment. The diffusion column $(28.5 \mathrm{~cm} \times 4.0 \mathrm{~mm}$ i.d.) was placed perpendicular to the center of the sampling column $l^{\prime}$ and $l$ of $[(57+57) \mathrm{cm} \times 4.0 \mathrm{~mm}$ i.d.], as shown in Figure 2. Both columns were connected by a $6.35 \mathrm{~mm}$ Swagelok tee union. The columns used in this chromatography were $6.35 \mathrm{~mm}$ diameter stainless-steel, unfilled with any solid material. All column sections were located inside the oven. The carrier gas was adjusted to a 1 $\mathrm{cm}^{3} \mathrm{~min}^{-1}$ continuously flows through the sampling column, while it is stagnant inside the diffusion column, L. A glass bottle $\left(2 \mathrm{~cm}^{3}\right)$ filled with methanol $\left(4 \mathrm{~cm}^{3}\right)$ was placed at the lower close end of the diffusion column, with a $6.35 \mathrm{~mm}$ Swagelok stainless nut.

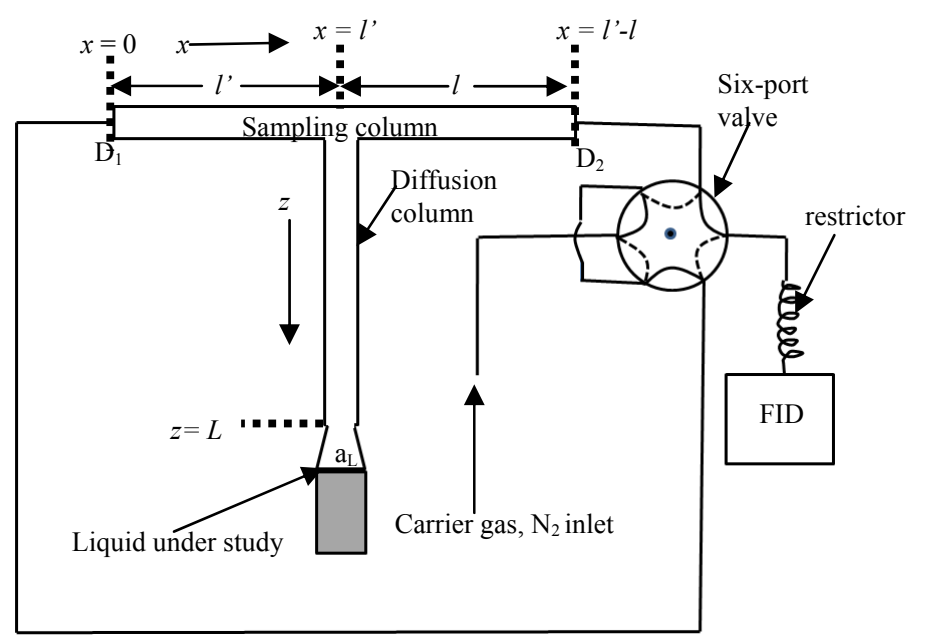

Fig. 2. The apparatus of the reversed-flow gas chromatography technique, for measuring rate coefficients and diffusion coefficients of liquids.

A six-port valve as shown in fig 2 was used to permit the carrier gas to enter either from $D_{2}$ and out at $D_{1}$ then immediately to the FID (valve position indicated by the solid line) or vice versa (the valve is switched to the dotted-line position). The valve reversed the direction of the carrier gas for $6 \mathrm{~s}$, which a shorter time period than the gas's hold-up time in both column section $l^{\prime}$ and $l$, then the gas was returned to its original direction, with resulting extra chromatographic peaks (sample peaks) superimposed on the continuous elution curve as depicted in fig 3.

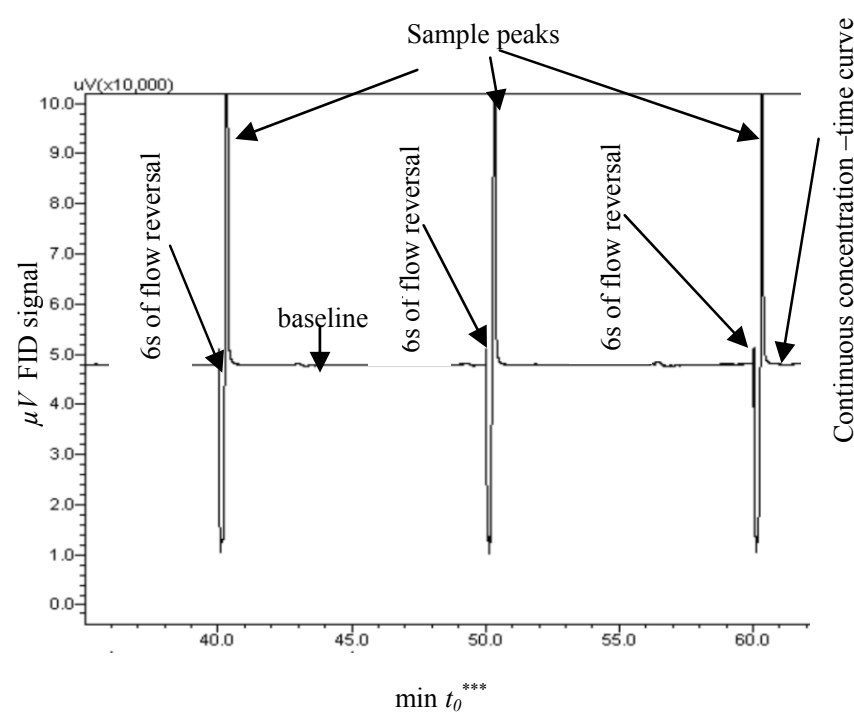

Fig. 3. A reversed flow chromatogram showing two sample peaks for the diffusion of liquid vapors into carrier gas nitrogen at $323.15 \mathrm{~K}$ and 101325 $\mathrm{Pa}$ (volumetric flow rate $=1 \mathrm{~cm}^{3} \mathrm{~min}^{-1}$ )

$* * * t_{0}=$ Time from the beginning to the last reversal of gas flow 
The process was repeated during the experiment, lasting for 5 hours and 40 minutes. The pressure drop along section $l$ ' and $l$ was negligible as the carrier gas flow rate was kept constant. $\left(1.0 \mathrm{~cm}^{3} \cdot \mathrm{s}^{-1}\right)$

\section{Theoretical basis}

The height, $h$ of the sample peaks from the continuous signal, taken from baseline to the maximum, was plotted as $\ln h$ versus time, giving a diffusion bands as shown in Fig. 4.

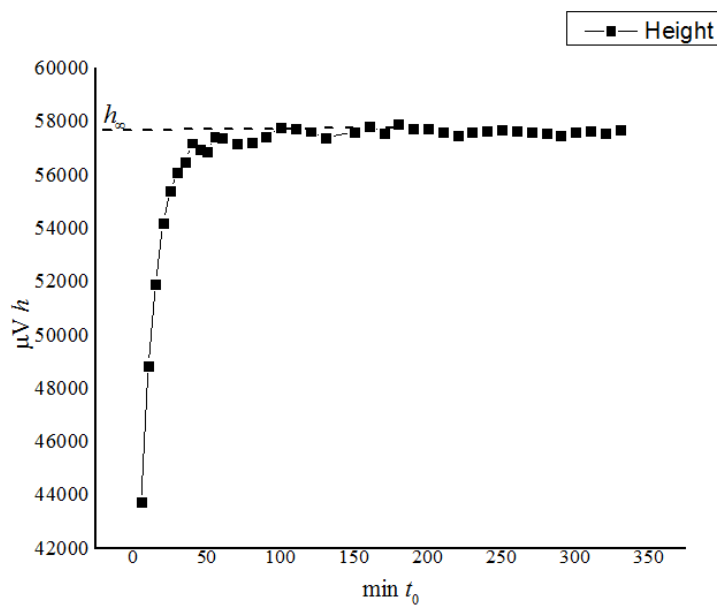

Fig. 4. Diffusion band (plot of sample peaks height, $h$, against time, $t_{0}$, from the beginning of the experiment) for the evaporation of liquid, at $313.15 \mathrm{~K}$ and $101325 \mathrm{~Pa}$.

Each sample peak which has been shown earlier [8], produced by two reversals in RF-GC, is symmetrical and its maximum height $h$ from the ending baseline is given by

$$
h \cong 2 c\left(l^{\prime}, t_{0}\right)
$$

Thus, the concentration of the vapors of an evaporating liquid, $c\left(l^{\prime}, t_{0}\right)$ at $x=l^{\prime}$ and time $t_{0}$ is proportional to the height or the area of the experimentally obtained sampling peaks, and it is interrelated with the rate coefficient for the evaporation process, $K_{G}$, the diffusion coefficient of the vapor into the carrier gas, $D$, and the geometrical details of the diffusion column through the relation [8]:

$c\left(l^{\prime}, t_{0}\right)=\frac{K_{G} D c_{0}}{V\left(K_{G} L+D\right)}\left\{1-\exp \left[-2\left(\mathrm{~K}_{G} L+D\right) t_{0} / L^{2}\right]\right\}$

where $L$ is the length of the diffusion column and $v$ the volumetric flow rate of the carrier-gas. Figure 5 represents the sampling of the above-mentioned process against time. It becomes obvious that after a period of time, which is characteristic of each particular interaction system, a steady-state situation is achieved. From this plot, at long times an infinite value for the peak height $h_{\infty}$ can be obtained. This infinity $h_{\infty}$ value is used for the linearization of the resulting relation [8]:

$$
h_{\infty}=\frac{2 K_{G} D c_{0}}{\left[v\left(K_{G} L+D\right)\right]}
$$

Using the former approximation, one obtains [8]:

$$
\ln \left(h_{\infty}-h\right)=\ln h_{\infty}-\left[\frac{2\left(K_{G} L+D\right)}{L^{2}}\right] t_{0}
$$

Thus, at long enough times, for which Eq. 4 was derived,a plot of $\ln \left(h_{\infty}-h\right)$ vs. $t_{0}$ is expected to be linear, and from its slope $-2\left(\mathrm{~K}_{G} L+D\right) / L^{2}$ a first value of $K_{G}$ can be calculated from the known value of $L$ and a literature or theoretically calculated value of $D$. [9] - [11]

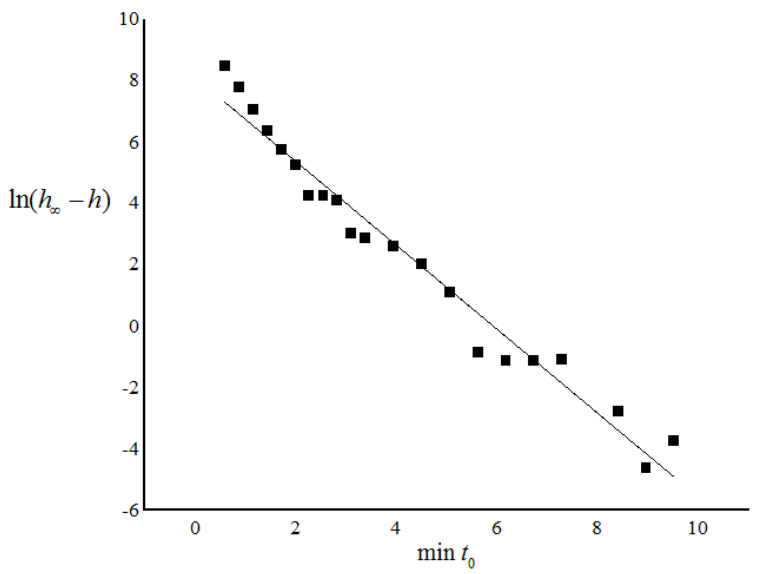

Fig. 5. Example of plot for the diffusion of liquid vapor into carrier gas at $313.15 \mathrm{~K}$ and $101325 \mathrm{~Pa}\left(v=1.00 \mathrm{~cm}^{3} \mathrm{~s}^{-1}\right)$

The value of $K_{G}$ can now be used to plot small time period data according to Eq. 14 of Ref. 9, which is substituted now for $c\left(l^{\prime}, t_{0}\right)$ in Eq. 2. After rearrangement, logarithms are taken and there results:

$$
\ln \left[\left(\frac{L}{2 t_{0}^{\frac{1}{2}}}+K_{G} t_{0}^{\frac{1}{2}}\right)\right]=\ln \left[\frac{4 K_{G} c_{0}}{v}\left(\frac{D L}{\pi}\right)^{\frac{1}{2}}\right]-\frac{L^{2}}{4 D} \frac{1}{t_{0}}
$$

Now a plot of the lefthand side of this relation versus $\frac{1}{t_{0}}$ will yield a first approximation experimental value for $D$ from the slope $\frac{-L^{2}}{4 D}$ of this new linear plot

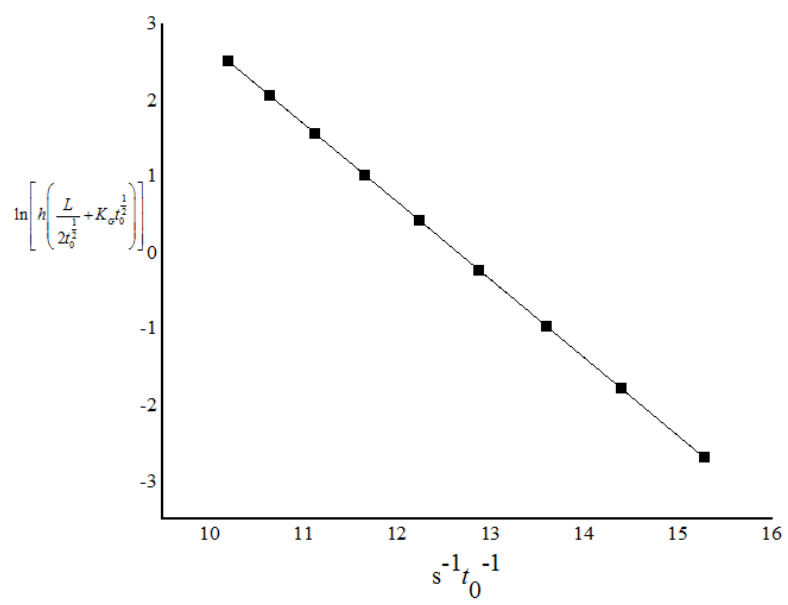

Fig. 6. Data from evaporation of liquid vapor into carrier gas at $323.15 \mathrm{~K}$ and $101325 \mathrm{~Pa}\left(V=1.00 \mathrm{~cm}^{3} \mathrm{sec}^{-1}\right)$, plotting according to Equation 7 


\section{RESULTS AND DISCUSSION}

TABLE I: RATE COEFFICIENTS FOR THE EVAPORATION OF METHANOL, $K_{\mathrm{G}}$, AND DIFFUSION COEFFICIENTS OF ITS VAPORS INTO NITROGEN, $D_{F O U N D}$, UNDER THE EFFECT OF VARIOUS AMOUNT OF SURFACTANT TRITON X-100, AT 313.15 AND 101325 PA

\begin{tabular}{|c|c|c|c|c|c|c|c|}
\hline $\begin{array}{c}\text { Monolayer Thickness of } \\
\text { Triton X-100 }\end{array}$ & $\begin{array}{c}10^{2} K_{\mathrm{G}}(\mathrm{cm} \\
\left.\mathrm{s}^{-1}\right)\end{array}$ & $\begin{array}{c}\text { Retardation of } \\
k_{c}, \%\end{array}$ & $\begin{array}{l}10^{3} D_{\text {found }} \\
/ \mathrm{cm}^{2} \mathrm{~s}^{-1}\end{array}$ & $10^{3} D_{\text {lit }} / \mathrm{cm}^{2} \mathrm{~s}^{-1}$ & $10^{3} D_{\text {lit }} / \mathrm{cm}^{2} \mathrm{~s}^{-1}$ & Deviation, $\%$ & Deviation, $\%$ \\
\hline 0 & $\begin{array}{c}96.69 \pm \\
0.20\end{array}$ & - & $181.8 \pm 0.04^{\mathrm{a}}$ & 184.31 & 200.58 & $1.4^{*}$ & $9.3^{\#}$ \\
\hline 1 & $\begin{array}{c}31.75 \pm \\
0.05 \\
\end{array}$ & 67.2 & $\begin{array}{c}189.23 \pm \\
0.02^{\mathrm{a}} \\
\end{array}$ & 184.31 & 200.58 & $2.6^{*}$ & $5.7^{\#}$ \\
\hline 2 & $\begin{array}{c}20.71 \pm \\
0.14\end{array}$ & 78.6 & $\begin{array}{c}188.07 \pm \\
0.02^{\mathrm{a}}\end{array}$ & 184.31 & 200.58 & $2.0^{*}$ & $6.2^{\#}$ \\
\hline 3 & $\begin{array}{c}17.31 \pm \\
0.07\end{array}$ & 82.1 & $\begin{array}{c}183.14 \pm \\
0.02^{\mathrm{a}} \\
\end{array}$ & 184.31 & 200.58 & $0.6^{*}$ & $8.7^{\#}$ \\
\hline 4 & $\begin{array}{c}12.30 \pm \\
0.31\end{array}$ & 87.3 & $\begin{array}{c}189.46 \pm \\
0.02\end{array}$ & 184.31 & 200.58 & $2.7^{*}$ & $5.5^{\#}$ \\
\hline & Mean values & & $\begin{array}{c}186.35 \pm \\
0.02\end{array}$ & & & $\left(1.9^{*}\right)^{\mathrm{c}}$ & $\left(7.1^{\#}\right)^{\mathrm{c}}$ \\
\hline
\end{tabular}

${ }^{\mathrm{a}}$ Uncertainty obtained from the standard error of the $k_{c}$ and $D$ values, estimated from the slopes of the linear plots of Eqs. 20 and 21 of Ref. 8 respectively.

${ }^{b}$ Precision determined from the mean value and the standard error of the experimentally obtained diffusion coefficients.

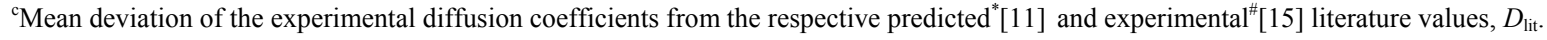

Table I summarizes the results for the evaporation of methanol under the influence of the surfactant Triton X-100 ranging from 0 to 4 monolayers. The diffusion coefficients which are determined from this experiment were compared with the predicted values from the Fuller-Giddings equation [11] and experimentally obtained values from previous experimental work [15] which was using a different method. The deviation of the diffusion coefficients of the current experiment from the predicted and experimental literature values, $D_{l i t}$ are illustrated in the last column and are based on the following equation:

$$
\operatorname{Deviation}(\%)=\left[\frac{\left(D_{\text {found }}-D_{\text {theoretical /literature }}\right)}{D_{\text {found }}}\right] \times 100
$$

Based on the diffusion coefficient values, $D_{\text {found }}$, ones can be assured that they are independent of the addition of surfactant, as expected [3]. The mean deviation of the methanol + Triton X-100 liquid mixtures experimental obtained by RF-GC, $D_{\text {found }}$, from the predicted and literature values are 1.9 and $7.1 \%$ respectively. The $D_{\text {found }}$ values falls between the predicted and literature ones. The total reproducibility of this method is determined $99.9 \%$ for the case of the liquid stated.

The uncertainty in the determination of the vaporization values, $k_{\mathrm{c}}$, varies from 0.2 to $2.5 \%$ in this case. Based on the percentages, we can conclude that the values experimentally obtained by use of RF-GC can be used to reliably predict the effect of Triton X-100 in the evaporation rates of methanol.

We can conclude that the $k_{\mathrm{c}}$ values in the presence of various amounts of Triton X-100 corresponding to the formation of an adsorbed monolayer at the surface of the methanol; demonstrating that Triton X-100 does make the evaporation rates decrease. The evaporation rate retards by a high percentage, i.e. $67.2 \%$; with just one monolayer of TritonX-100 being applied on the surface of the methanol.

\section{CONCLUSION}

The present method gives an alternative from the previous method [15], since the former method can be used in simultaneously determining the evaporation rates and diffusion rates of the liquid under study. The present method can be considered accurate since the results show that the diffusion in the current experiment deviates from the predicted theoretical value by less than $2.0 \%$ (based on mean values); as compared from the works by Anikar H.J. et. al. [15]. Also, the use of RF-GC has value because of its precision and experimental simplicity.

The evaporation rates found by the current experiment are absolute and as a result they can be related to the physical properties of the evaporating species.

We can obviously extend the use of RF-GC to other topics that are related to the environmental, such as investigation of water evaporation (sea, lake, river), the effect of ionic and zwitterionic surfactants on the evaporation rates of liquid pollutants; as well as experiments with surfactants under steering conditions in order to investigate their durability[3].

\section{ACKNOWLEDGMENTS}

The author is indebted to the University of Malaya which supported this research project. The author wants to dedicate special thanks to Dr. Tay Kheng Soo for his critique and review of the findings from the experiments; as well as to the staff of the Department of Chemistry, University of Malaya, for their technical support. The author is also indebted to Miss Kumuthini A/P Chandrasekaram for her assistance on tensiometer usage.

\section{REFERENCES}

[1] K. Khalid, A. K. Rashid, M. Z. Sharifuddin, "Analysis of The Liquid Pollutant Using RF-GC Methodologies," in Proc. 2010 IJESD Conf., 2011, pp. 2.2-1-2.2-6.

[2] R. Sario, R. Ahmad. (2012, July 12). Tanker explosion in Labuan leaves one dead, four missing (Update). The Star. Retrieved from http://thestar.com.my/news/story.asp?file $=/ 2012 / 7 / 26 /$ nation $/ 2012072$ $6110701 \& \sec =$ nation 
[3] G. Dimitrios, A. K. Rashid, G. Karaiskakis, "Study of the evaporation of Pollutant Liquids under the Influence of Surfactant," AlChE, 2006, vol. 52, pp.2381-2389.

[4] K. Khalid, A. K. Rashid, M. Z. Sharifuddin, "Analysis of Diffusion Coefficient using Reversed-Flow Gas Chromatography- A Review," Am. J. Applied Sci., 2011, vol.8, no.5, pp. 428-435.

[5] M. J. Rosen, Surfactants and Interfacial Phenomena, John Wiley \& Sons, NY, 1989, pp. 67-68.

[6] Robert J. States and Chester S. Gardner, "Thermal Structure of the Mesopause Region $(80-105 \mathrm{~km})$ at $40^{\circ} \mathrm{N}$ Latitude. Part I: Seasonal Variations," Journal of the Atmospheric Sciences, 2000, vol.57, pp. 66-67.

[7] Lainiotin G Ch, J. Kapolos, A. Koliadiama, G. Karaiskakis, $J$ Chromatogr A, 2010, vol.1217, pp.1813-1820.

[8] Karaiskakis G, Katsonas NA., "Rate coefficients for evaporation of pure liquids and diffusion coefficients of vapors," J Phys Chem, 1984, vol.88, pp. 3674-3678.

[9] G. Karaiskakis, D. Gavril, “ Determination of diffusion coefficients by gas chromatography," J Chromatogr A. 2004, vol.1037, pp.147-189 (Review).

[10] Transport Phenomena, R.B. Bird, W. E. Stewart, E.N. Lightfoot, John Wiley\& Sons, NY, 1960, pp. 511

[11] E. N. Fuller, P. D. Shettler, J. C. Giddings, "A new method for prediction of binary gas-phase diffusion coefficients," Ind Eng Chem. 1966, vol.58, pp.18-27.

[12] K. Khalid, A. K. Rashid, M. Z. Sharifuddin, "Determination of Rate Coefficients and Diffusion Coefficients of Butanol Using RF-GC Methodhologies," Studia Ubb Chemia, LVI. 2011, vol. 2, pp.149-154.

[13] K. Khalid, A. K. Rashid, Sharifuddin M. Z., "Determination of Diffusion Coefficients of Selected Long Chain Hydrocarbon Using Reversed-Flow Gas Chromatography Technique," E-Journal of Chemistry, 2011,vol. 8 no.4, pp.1916-1924.

[14] K. Khalid, A. K. Rashid, and M. Z. Sharifuddin, "Determination of Diffusion Coefficients and Activation Energy of Selected Organic Liquids Using Reversed-Flow Gas Chromatography Technique," Sains Malaysiana, 2012, vol.41 no.9, pp.1109-1116.

[15] H. J. Arnikar, H. M. Ghule, "Electrodeless discharge as detector in the rapid determination of binary diffusion coefficient of gases," Int $J$ Electronics.1969, vol.26, pp.159-162.

[16] V. K. Lamer, Retardation of evaporation by monolayers. 1962, New York: Academic Press.

[17] K. Lukenheimer and M. Zembala, "Attempts to Study a Water Evaporation Retardation by Soluble Surfactants," Journal of Colloid and Interface Science, 1997, 188, pp. 363-371.

[18] D. N. Bull and L. L. Kempe, "Influence of surface active agents on oxygen absorption to the free interface in a stirred fermentor," Biotechnology and Bioengineering, 1971. vol. 13, no. 4, pp. 529-547.

[19] J. T. Davies and E. K. Rideal, Interfacial Phenomena. 1961, New York Academic Press.

[20] F. Goodridge and I. D. Robb, Mechanism of interfacial resistance in gas absorption, Ind. Eng. Chem. Fundam., 1965. vol. 4, pp. 49-55.

[21] G. T. Barnes, The effects of monolayers on the evaporation of liquids. Advances in Colloid and Interface Science, 1986. vol. 25, pp. 89-200.

[22] Hsin, Y.-L.L., "Feasibility Experiments into the Use of Hexadecanol for Hurricane Mitigation and the Planning and Construction of the Monolayer Evaporation Retardation Laboratory," Department of Material Science and Engineering, 2002, Massachusetts Institute of Technology: Massachusetts, pp. 25 .

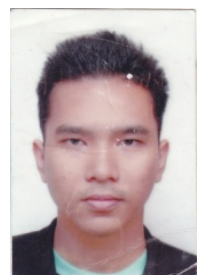

Mohammad Hafiz Bin Hamzah was born in 1987 in Lumut, Perak, Malaysia. He obtained the Bachelor of Degree in Education (majoring in chemistry) from University of Malaya in the year of 2011. He is currently pursuing master degree full time by research in the same institution in the field of analytical chemistry.

He has experienced on teaching secondary school for a year before deciding to continue his studies in area of chemistry. Mr. Hamzah is also one of the recipients of fellowship from University Malaya under the "Skim Biasiswazah", the prestigious fellowship given by the university to undergraduate student to pursue higher degree.

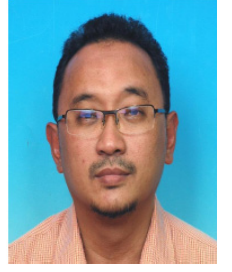

Sharifuddin Bin Md. Zain obtained Bachelor of Science from Imperial College of Science Technology and Medicine and got his $\mathrm{PhD}$ from the same institution.

$\mathrm{He}$ is currently the head of Chemistry Department, University Malaya. He is expert in Chemical Sciences (Computational Chemistry, Chemometrics, Computers in Chemical Education). Prof. Zain received recognition from international body which includes 1 st Prize Smart Learning Software: Multimedia Development Corporation MSCAPICTA- Asia Pacific IT Awards (April 2002). QASIM : Application of Qualitative Reasoning in Chemical Education - Inorganic reactions at STPM/SPM level. ,Multimedia Development Corporation MSC-APICTA, 2002 and JSPS-VCC Visiting Scientist, Japan Society for Promotion of Science, 2001. He is currently a member of Persatuan Sains Analisis Malaysia, since 2004, (National) as well as Royal College of Science, as Associate Member, since 1991, (International).

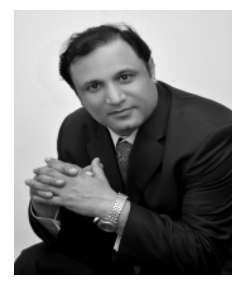

Rashid Atta Khan received his PhD from University of Patras, Athens, Grecee back to 2006. His Phd thesis entitled "Development of new chromatographic methods for the study of exchange of pollutants between the atmosphere and the water environment" has made an impact in the field of Reversed-Flow Gas Chromatography since he got the directly supervised by the inventor of the methodologies which is G. Karaiskakis. He major interest is in analytical chemistry.

Assc. Prof. Khan is currently a member of Ameican Chemical Society, since 2009, and The chemical society of Paksitan, Member, since 2004. He is also a course co-ordinator SCES 3311, Advance Analytical Chemistry, University Malaya, from 01-Jan-07 to 01-Jul-12.

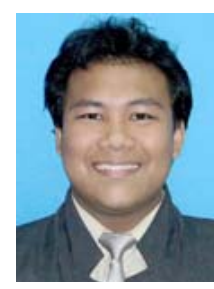

Khalisanni Khalid was born in Ipoh in 1985. He pursued his studies in Universiti Teknologi MARA (UiTM) and graduated with a BSc. (Hons.) in Applied Chemistry at the end of 2007. After a year as a research assistant in University of Malaya, he was offered the University Malaya Fellowship (UM), Postgraduate Study Scheme (KPT), Postgraduate Dana (MOSTI) and National Science Fellowship (NSF). He chose National Science Fellowship to read the master's degree in Universiti Malaya.

Upon study, he was appointed as residential assistance for PERMATAPintar Program in Universiti Kebangsaan Malaysia. He flew away to Thailand and Singapore to give the speech on his research. His diligence was rewarded with a degree in Master of Science in Physical/ Environmental Sciences in 2011. Before graduation, he was offered to join Malaysian Agricultural Research and Development Institute (MARDI) There onwards, his interest of research in science and business grew. This was further encouraged by the recognition and support from MARDI, where he was appointed as Technical Officer for MARDI Kuala Linggi Incubator Program. This project leads him to train SMEs for essential oil production. In MARDI Headquarters Serdang, he is responsible to lead Essential Oil Analysis Unit under Food and Agricultural Analysis Laboratory Program, Technical Service Centre. He is also the gatekeeper for Malaysian Herbal Authentication Centre (MHAC).

Mr. Khalid has exposed over 5 years in diverse research areas especially research ethics, essential oil, polymer, biofuel, fermentation, analytical and environmental chemistry. He has been honoured and recognised both nationally and internationally for his research creativity and innovativeness. At his age of 28 , he has published more than 60 articles in books, book chapters, and proceedings of which more than 30 articles in refereed journals. 